\title{
EDITORIAL: TIME AND STYLE
}

\author{
Christopher Fox
}

Not time and tide, nor style and idea, but somewhere in between. As TEMPO sets out on another volume perhaps this is a good moment to think about what's in and what's out, to think about suitable subjects and suitable ways of discussing them.

TEMPO is a review of new music, yet this issue includes an article about the final piano sonata by Michael Tippett, a work written in the last century by a composer born almost at the beginning of that century. This issue also includes an article that reaches back to the early years of the Cold War and speculates on possible connections between the development of, on the one hand, surveillance technology and, on the other, electronic and computer music. Yet, quite often, potential contributors send in articles which are rejected on the grounds that they are about subjects too far in the past. How far is too far?

If late Tippett and Cold War spookery are suitable subjects for a review of new music, it is because the issues they raise continue to resonate in the newest music. Thus Philip Mead's article on Tippett is not only a companion piece to Toby Young's consideration of the same composer's Fourth Symphony in TEMPO 277 but it also raises questions about a performer's understanding of a work. As long as new music practice - some of it, at least - involves musicians playing from notation, it will remain interesting to think about the point at which the performer of a piece of music becomes a more reliable witness than its composer. Similarly, Robin Maconie's article on Boulez and the links between voice recognition technology and computer music offers both a fascinating exploration of the ways in which apparently unrelated events might be more closely connected than we thought and a model for thinking about the ways in which contemporary artists are responding to big data and post-internet ideologies.

Some of those ideologies played out in Darmstadt this summer, during the Ferienkurse für neue Musik, and this issue of TEMPO includes two reviews of the Ferienkurse and an extended essay in which Donal Sarsfield attempts to give a sense of how the Ferienkurse played out for him. Too much Darmstadt? Perhaps. But that is itself a characteristic Darmstadt experience. Since no one can even attend, let alone see and hear everything that happens across a 20-day, multi-centred assemblage of classes, seminars, concerts, how can one describe what happened? In what is something of an experiment for TEMPO we publish three very different accounts, all of them partial.

They are also stylistically different, and this too is something of an experiment. TEMPO is published by an academic press, but is not an academic journal, even if it adopts many of the manners of one. Nevertheless some readers will probably object that Sarsfield's essay and Max Erwin's Darmstadt review are too subjective, that their writers have placed themselves too firmly in the foreground of the musical landscape they are describing. I understand such objections 
but I think that sometimes we confuse what we say with how we say it. A complex prose style may not guarantee critical rigour, nor lightness always signify triviality, and if TEMPO takes seriously its role as a review of new music we should perhaps be prepared to think about whether there may be different ways of expressing that seriousness.

It is with regret that we note the death of Peter Reynolds (1958-2016). Peter was a regular contributor to TEMPO - his last review was published in TEMPO 278 - but, perhaps more significantly, he was a composer and a tireless advocate for new music in his native Wales. He was artistic director of the PM Music Ensemble, which he formed in 1991, and the Lower Machen Festival, and launched a series of free foyer concerts at Wales Millennium Centre which presented some 500 performances every year between 2004 and 2007; he also taught composition at the Royal Welsh College of Music and Drama. In 2009 his book, The BBC National Orchestra of Wales; a celebration, was published by the BBC.

For TEMPO his reviews were typically generous in their remarks about fellow musicians but, like all the best reviewers, he also mixed generosity with objectivity; reading a Reynolds review one always had a clear sense of how the music sounded. He began his last review for TEMPO with a question - 'how do you deal with endings? - and in the responses to the news of his death from his many friends across the musical world the answer has been the same: 'with great sadness'. 